\title{
Artritis séptica en pacientes adultos en un hospital general de Chile
}

\author{
Constanza Florestano, Alberto Fica, Natalia Gaete, Lorena Porte y Stephanie Braun
}

\section{Septic arthritis in adult patients in a general hospital in Chile}

Background: Septic arthritis is an infrequent condition of prolonged morbidity and there is no previous publications in Chile that allow orientate therapy. Aim: To characterize a group of adult patients with septic arthritis confirmed by culture. Material and Methods: Descriptive study of a case series. Results: From 2003 to august 2013, 24 patients with 25 events of septic arthritis were identified in a general hospital. Mean age was 68.3 years old (range 24-94). Predisposing conditions were harbored by $91.7 \%$. Predominant clinical manifestations were pain (92\%) and impaired joint movement (95.7\%). Fever was present in $64 \%$, hypotension in $28 \%$ of events, and C-reactive protein $>100 \mathrm{mg} / \mathrm{L}$ in $90.6 \%$. Gram positive cocci were the most frequently isolated microorganisms (81.5\%), predominating $S$. aureus $(48.1 \%)$, and with 4 isolates methicillin resistant isolates (26.7\%). Resistant isolates trend to be associated with previous surgery $(\mathrm{p}=0.055)$ and all cases caused by non-fermentative Gram negative bacilli had recent hospitalization or surgery, a feature that did not reach a significant difference. Nine events were associated to bacteremia (36\%). Outcome analysis indicated $32 \%$ of events with full recovery, $28 \%$ with a favorable evolution, $20 \%$ with therapy failure and $16.7 \%$ patients that died. A total of $24 \%$ of the series remained with significant sequels. Conclusions: Septic arthritis is an infrequent disease that affects in most cases patients with predisposing conditions. Associated symptoms include pain and impaired joint movement, sometimes fever, hypotension, positive blood cultures and frequently a C-reactive protein $>100 \mathrm{mg} / \mathrm{L}$. Predominant agents are Gram positive cocci, specially $S$. aureus, including methicillin resistant isolates. Case-fatality ratio, treatment failure and sequels are important.

Key words: Infectious arthritis, bacteremia, Staphylococcus aureus, arthroscopy, case fatality rate, adult.

Palabras clave: Artritis séptica, bacteriemia, Staphylocococcus aureus, artroscopia, letalidad, adulto.

\section{Introducción}

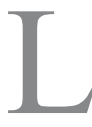

os cuadros de artritis séptica en pacientes adultos son de baja ocurrencia pero de alta morbilidad, con hospitalizaciones prolongadas, procedimientos invasores asociados, secuelas y letalidad. Se estima una incidencia de 10 casos por 100.000 habitantes y cerca de 70 por 100.000 entre pacientes con artritis reumatoidea (AR) o prótesis articular ${ }^{1}$. La mayor parte se adquiere por vía hematógena, favorecida por el hecho anatómico que el tejido sinovial carece de una membrana basal. Estos eventos se asocian a diferentes etiologías bacterianas e incluso fúngicas y la descripción de los agentes prevalentes es necesaria para diseñar esquemas empíricos antimicrobianos con cobertura adecuada. No existen publicaciones en Chile al respecto y la literatura médica disponible está restringida a reportes de pocos $\operatorname{casos}^{2-5}$ o resultados de la experiencia terapéutica artroscópica en el manejo de esta patología ${ }^{6}$. Es necesaria entonces, la revisión de una serie de pacientes con esta patología en nuestro país. Varias interrogantes necesitan ser aclaradas. Por ejemplo, se desconoce cuál es el perfil demográfico de estos pacientes, qué co-morbilidades tienen, qué proporción está asociada a prótesis articulares o a procedimientos intra-articulares previos. Tampoco hay información sobre los patógenos más prevalentes, su perfil de resistencia y los factores asociados a ella. Con el objeto de aclarar algunos de estas interrogantes, se efectuó un trabajo retrospectivo en pacientes adultos afectados por artritis séptica en un hospital general.

\section{Pacientes y Métodos}

Los casos fueron identificados a través del registro disponible en el Laboratorio de Microbiología del Hospital Militar de Santiago (HOSMIL), desde el año 2003. El HOSMIL es un centro de 250 camas que atiende al personal militar activo o retirado, sus cargas y pacientes de libre demanda. Se usó un diseño retrospectivo, descriptivo, tipo serie clínica y se incluyeron pacientes $\geq 18$ años, con cultivo articular positivo y un cuadro clínico compatible, definido por la presencia de cualquier molestia articular o anomalía al examen físico articular. No
Universidad de Valparaíso. Valparaíso, Chile. Programa de Formación en Medicina Interna (CF). Hospital Militar de Santiago, Santiago, Chile.

Servicio de Infectología (AF) Departamento Laboratorio Clínico (LP, SB).

Universidad de Los Andes. Santiago, Chile.

Internado de Medicina (NG)

Conflicto de interés: ninguno Financiamiento: ninguno

Recibido: 11 de noviembre de 2013 Aceptado: 4 de febrero de 2014

Correspondencia a: Alberto Fica Cubillos albertofica@gmail.com 
se incluyeron casos con estudio microbiológico negativo por la incertidumbre diagnóstica. El estudio fue aprobado por el Comité de Ética del HOSMIL.

Los datos fueron extraídos desde las fichas clínicas mediante una plantilla estructurada. Se incluyó información demográfica, antecedentes mórbidos generales y de relevancia para este tipo de infecciones: prótesis o cirugía articular previa en el sitio involucrado, diabetes mellitus, AR, alcoholismo, inmunosupresión, cáncer, enfermedad renal crónica, infección cutánea cercana reciente e infiltraciones articulares. Se incluyeron parámetros básicos del examen físico, hallazgos del examen físico articular, sitio afectado y variables de laboratorio que incluyeron características del líquido articular y valores de proteína $\mathrm{C}$ reactiva (PCR). Se analizaron también los estudios de imágenes efectuados, se registró la unidad de hospitalización de mayor complejidad, el tratamiento antimicrobiano, su espectro y oportunidad (adecuado si se inició en las primeras $24 \mathrm{~h}$ ), tipo y número de aseos (por artrocentesis, artrotomía o artroscopia), los resultados de los cultivos articular y sangre y la susceptibilidad antimicrobiana de los agentes involucrados. Además, se registró el desenlace en la hospitalización respectiva y las secuelas en los sobrevivientes.

\section{Definiciones}

Curación: mejoría clínica completa sin evidencias de recaída ni secuelas. Respuesta favorable: mejoría clínica pero asociada a la necesidad de aplicar un tratamiento de supresión, recaída, secuelas, o tiempo de seguimiento $<2$ años en infección asociada a prótesis articular. Fracaso: persistencia de la sintomatología o necesidad de remover la prótesis articular afectada. Se consideró el evento como infección asociada a la atención de salud (IAAS) si el cuadro afectó una articulación intervenida con instalación de prótesis o material de osteosíntesis en los 12 meses anteriores al episodio de artritis séptica, con microbiología

Tabla 1. Condiciones predisponentes asociadas en 24 pacientes con artritis séptica, Hospital Militar de Santiago 2003-2013

\begin{tabular}{lcc} 
Condición & $\mathbf{n}$ & $\%$ \\
Diabetes mellitus tipo 2 & 13 & 54,2 \\
Prótesis articular & 11 & 44,0 \\
Enfermedad renal crónica en diálisis & 3 & 12,5 \\
Cáncer & 3 & 12,5 \\
Alcoholismo (sin daño hepático asociado) & 3 & 12,5 \\
Cirugía articular previa sin prótesis & 2 & 8,3 \\
Daño hepático crónico & 2 & 8,3 \\
Artritis reumatoidea & 2 & 8,3 \\
Cualquier condición asociada & 22 & 91,7 \\
\hline
\end{tabular}

\begin{tabular}{|lcc|}
\hline \multicolumn{2}{|c|}{ Tabla 2. Sitio afectado en } & 25 eventos de artritis séptica, \\
Hospital Militar de Santiago & 2003-2013 \\
Sitio & $\mathbf{n}$ & $\%$ \\
Rodilla & 9 & 36 \\
Cadera & 9 & 36 \\
Hombro & 3 & 12 \\
Tobillo & 3 & 12 \\
Muñeca & 1 & 4 \\
Total & 25 & 100 \\
\hline
\end{tabular}

compatible o se efectuó algún procedimiento artroscópico diagnóstico o terapéutico en el último mes.

\section{Análisis estadístico}

La información de variables numéricas fue resumida en forma descriptiva y también categorizada en grupos dicotómicos para facilitar el análisis. Para la identificación de potenciales factores de riesgo asociados a infecciones protésicas, infecciones estafilocóccicas o por bacilos gramnegativos no fermentadores (BGNNF) o agentes resistentes, se efectuó un análisis univariado con las variables categóricas o numéricas categorizadas, utilizando el $\chi^{2}$ (paramétrico) o test exacto de Fisher (no paramétrico) según el número de casos por celda. Se utilizó un nivel de significancia $\mathrm{p}<0,05$.

\section{Resultados}

Un total de 24 pacientes con 25 eventos de artritis séptica fueron identificados entre enero de 2003 y agosto de 2013 (0-5 eventos por año). La distribución por sexo hombre: mujer fue similar (13:11) y la edad promedio fue de 68,3 años (rango 24-94).

Condiciones predisponentes. (Tabla 1). Predominaron diabetes mellitus tipo 2 y la presencia de prótesis articular. Otros factores conocidos incluyeron pacientes en diálisis (n: 3), con cáncer hematológico (n: 2) o sólido (n: 1), cirugía articular no asociada a prótesis (n: 2), daño hepático crónico y alcoholismo sin cirrosis asociada (n: 3) o AR (n: 3). Los dos pacientes con AR no estaban en tratamiento inmunosupresor al momento del evento. La mayor parte de los pacientes tuvo al menos una condición de riesgo $(91,7 \%)$.

Todos los pacientes se presentaron con monoartritis. Los sitios más afectados fueron rodilla y cadera (Tabla 2). Cuatro casos (16\%) representaron infecciones del sitio quirúrgico (todos en cirugía de cadera) y otros dos casos infecciones post artroscopia de rodilla (8\%). Estos seis casos se consideraron como IAAS, representando $24 \%$ de la serie (n: 6). 
El dolor e impotencia funcional constituyeron las manifestaciones más relevantes y constantes en esta serie de pacientes (Tabla 3). Dos tercios de los casos presentaron fiebre al igual que el aumento de volumen; su ausencia estuvo significativamente asociada a la presencia de una prótesis articular comprometida $(\mathrm{p}<0,05)$. El eritema fue un hallazgo infrecuente. La presencia de fístula o dehiscencia estuvo significativamente asociada al antecedente de cirugía articular previa ( $\mathrm{p}<0,05$ por prueba bilateral de Fisher). Pocos pacientes se presentaron con compromiso de conciencia y la hipotensión arterial al ingreso estuvo presente en casi $30 \%$ de los casos, rasgo que no estuvo asociado a la presencia de bacteriemia (Tabla 3).

Tres de los 25 eventos se presentaron luego de la hospitalización del paciente por otra causa (rango 3 a 54 días de hospitalización). El resto (n: 22;88\%), se presentó como cuadros de debut comunitario con un rango de 0 a 184 días sintomáticos antes del ingreso (promedio 26,2 días). La mediana de estos casos fue cinco días de evolución.

En siete eventos se detectaron alteraciones cutáneas concomitantes o precedentes al cuadro de artritis séptica (28\%) y que incluyeron úlcera venosa (n: 1), necrosis de ortejo (n: 1), herida operatoria infectada (n: 1), infección cutánea precedente (n: 2), síndrome de Sézary (n: 1) y escara sacra (n: 1). Sólo en tres de estos casos la lesión era contigua al foco articular. La infección por vía hematógena fue la más frecuente (n: 16; 64\%), secundada por inoculación (n: $6 ; 24 \%$ ) y luego por contigüidad (n: $3 ; 12 \%$ ).

Los niveles promedio de hemoglobina $(11,7 \mathrm{~g} / \mathrm{dL}$, rango 8,6-16,5) y de albuminemia $(3,5 \mathrm{~g} / \mathrm{dL}$, rango 2,5-4,5) fueron prácticamente normales. Se observó, en promedio, leucocitosis, neutrofilia, aumento de PCR, velocidad de eritrosedimentación elevada, hiperglicemia y ascenso de nitrógeno ureico, aunque el porcentaje real de pacientes con valores elevados de leucocitos o de neutrofilia fue reducido (Tabla 4). Así, sólo 24\% (n: 6) de los eventos se asoció a leucocitosis $>15.000 / \mathrm{mm}^{3}$ y $37,5 \%$ (n: 9) a neutrofilia $>10.000 / \mathrm{mm}^{3}$. En contraste, $90,6 \%$ (n: 20) de los eventos tuvo valores de PCR $>100 \mathrm{mg} / \mathrm{L}$.

\section{Estudio de imágenes}

El examen más solicitado fue la ecografía (n: 10;44\%), luego radiografía simple (n: $9 ; 36 \%$ ), cintigrafía ósea (n: $4 ; 16 \%)$, tomografía axial computada-TAC (n: $4 ; 16 \%)$ y resonancia magnética-RM (n: $1 ; 4 \%)$. La ecografía fue significativamente menos solicitada en caso de infección asociada a una prótesis articular (OR 0,$09 ; \mathrm{IC}_{95}$ 0,0130,62, p < 0,05). El cintigrama óseo sólo fue solicitado en pacientes con prótesis articular o material de fijación $(\mathrm{p}<0,05)$ y tres de los cuatro exámenes de TAC fueron solicitados en pacientes bajo esta misma condición. Un quinto de los pacientes (n: 5) no tuvo estudio de imágenes antes del procedimiento diagnóstico.
Tabla 3. Síntomas y signos registrados en 25 eventos de artritis séptica, Hospital Militar de Santiago 2003-2013

\begin{tabular}{|lcc|} 
Manifestación clínica & $\mathbf{n}$ & $\%$ \\
Dolor & 23 & 92,0 \\
Impotencia funcional & 22 & 95,7 \\
Fiebre & 16 & 64,0 \\
Aumento de volumen & 16 & 64,0 \\
Eritema & 5 & 20,0 \\
Fístula o dehiscencia de herida & 4 & 16,0 \\
Compromiso de conciencia & 3 & 12,0 \\
Hipotensión arterial & 7 & 28,0 \\
\hline
\end{tabular}

Tabla 4. Parámetros de laboratorio al ingreso en pacientes hospitalizados por artritis séptica. Hospital Militar de Santiago 2003 al 2013

\begin{tabular}{|lccc|} 
Variable & $\mathbf{n}$ & Promedio & rango \\
Leucocitos/mm & 25 & $12.467,2$ & $2.600-26.130$ \\
Neutrófilos/mm & 25 & $10.056,6$ & $930-24.562$ \\
Eritrosedimentación mm/h & 24 & 58,4 & $2-117$ \\
Glicemia $\mathrm{mg} / \mathrm{dL}$ & 25 & 166,3 & $86-531$ \\
Nitrógeno ureico $\mathrm{mg} / \mathrm{dL}$ & 22 & 24,4 & $11-58$ \\
Proteína C reactiva $\mathrm{mg} / \mathrm{L}$ & 22 & 179,3 & $3,1-364$ \\
\hline
\end{tabular}

En los 11 casos con estudio ecográfico, las alteraciones observadas fueron colección (n: $5 ; 45,5 \%$ ), aumento del líquido articular (n: 4; 36,4\%), sinovitis (n: 3; 27,3\%), o elementos en suspensión (n: $2 ; 18,2 \%$ ). En dos casos no se observaron alteraciones $(18,2 \%)$. Las radiografías convencionales fueron solicitadas en seis pacientes con prótesis y en uno de ellos reveló aflojamiento y en otro luxación. Fue solicitada también en tres pacientes sin prótesis, revelando disminución del espacio articular. En dos de los cuatro estudios cintigráficos se observó aumento de la actividad osteoblástica en forma alejada al momento de la intervención ( $>2$ años), lo que podría interpretarse como sugerente de osteomielitis asociada a la prótesis articular: En los dos casos restantes también se observó mayor actividad pero en forma cercana al momento quirúrgico, lo que no hace evaluable este examen. La TAC fue solicitada en cuatro ocasiones demostrando radiolucidez periprotésica en un caso y aumento de tejidos blandos en dos.

\section{Características macroscópicas, estudio del líquido articular y hallazgos microbiológicos}

Hubo pus visible al momento de la punción o cirugía en cerca de la mitad de los casos de esta serie (12 de 25; $48 \%)$. Sólo en seis casos (25\%) se contó con información del líquido articular (Tabla 5). Se puede apreciar una 
gran dispersión en los valores de recuento de leucocitos y neutrófilos. Los hallazgos más importantes fueron el alto porcentaje de neutrófilos y la baja concentración de glucosa articular. Cuatro de los seis casos tuvieron glucosa $<27 \mathrm{mg} / \mathrm{dL}(75 \%)$. En cinco de estos seis casos, se observaron bacterias en la tinción de Gram $(83,3 \%)$.

En 23 de los 25 eventos la infección fue monomicrobiana $(92 \%)$ y polimicrobiana en dos. Las cocáceas grampositivas superaron el $80 \%$ de los casos; predominó Staphylococcus aureus, especie que representó casi la mitad de todos los casos (Tabla 6). Una diversidad de otras especies estafilocóccicas y estreptocóccicas fue identificada en el resto de los casos asociados a este grupo, incluyendo un evento por Enterococcus faecalis. Cuatro de los $15(26,7 \%)$ aislados estafilocóccicos identificados en este trabajo presentaron resistencia a cloxacilina, en tres casos $S$. aureus y en un caso Staphylococcus epidermidis; las cepas resistentes tendieron a estar asociadas

Tabla 5. Características del estudio articular en 6 casos de artritis séptica con información disponible. Hospital Militar de Santiago, 2003-2013

\begin{tabular}{lrc} 
Parámetro de laboratorio & Mediana & Rango \\
Recuento leucocitos $/ \mathrm{mm}^{3}$ & 13.400 & $6.600-180.000$ \\
Recuento neutrófilos $/ \mathrm{mm}^{3}$ & 11.040 & $6.270-144.000$ \\
\% de neutrófilos & 87 & $80-98$ \\
Recuento mononucleares $/ \mathrm{mm}^{3}$ & 2.015 & $134-36.000$ \\
\% de mononucleares & 13 & $2-20$ \\
Glucosa articular $\mathrm{mg} / \mathrm{dL}$ & 12 & $0-221$ \\
\hline
\end{tabular}

Tabla 6. Hallazgos microbiológicos en 25 eventos de artritis séptica. Hospital Militar de Santiago, 2003-2013

\begin{tabular}{lrrll} 
Agente involucrado & $\mathbf{n}$ & \multicolumn{1}{c}{$\%$} & Comentarios \\
Grampositivos & & & \\
Staphylococcus aureus & 13 & 48,1 & 3 cepas con resistencia a cloxacilina \\
Streptococcus agalactiae & 2 & 7,4 & \\
Staphylococcus capitis & 1 & 3,7 & \\
Staphylococcus epidermidis & 1 & 3,7 & 1 cepa con resistencia a cloxacilina \\
Enterococcus faecalis & 1 & 3,7 & \\
Streptococcus mutans & 1 & 3,7 & \\
Streptococcus pyogenes & 1 & 3,7 & \\
Streptococcus salivarius & 1 & 3,7 & \\
Streptococcus grupo G & 1 & 3,7 & \\
Subtotal & 22 & 81,5 & \\
Gramnegativos & & & \\
Pseudomonas aeruginosa & 3 & 11,1 & Hospitalización reciente o cirugía articular previa \\
Acinetobacter baumannii & 1 & 3,7 & Hospitalización reciente \\
Escherichia coli & 1 & 3,7 & \\
Subtotal & 5 & 18,5 &
\end{tabular}

a cirugía articular previa pero sin alcanzar significación estadística ( $p$ : 0,055). Todos los casos asociados a BGNNF tenían antecedentes de hospitalización reciente o cirugía articular previa aunque este hallazgo no alcanzó una significancia estadística.

\section{Casos con bacteriemia}

Nueve eventos $(36 \%)$ se asociaron a bacteriemia, siete de ellos causados por $S$. aureus y uno cada uno por Pseudomonas aeruginosa y Streptococcus agalactiae, respectivamente. Se exploraron diferentes variables categóricas para buscar su asociación con bacteriemia. Sólo el compromiso de conciencia apareció relacionado positivamente con este hallazgo. Los tres pacientes con compromiso de conciencia tuvieron bacteriemia sin observar este rasgo en los pacientes sin bacteriemia (OR 3,5; IC95 1,7-6,9 p < 0,05). En contraste, los pacientes con cirugía articular previa tuvieron con menos frecuencia bacteriemia; sólo uno de 11 con cirugía previa versus ocho casos de bacteriemia entre 12 pacientes sin cirugía previa (OR 0,04; IC95 0,004-0,48 p < 0,01).

\section{Casos asociados a prótesis articular}

Once eventos $(44 \%$,) estuvieron asociados a prótesis articular (Tabla 1). Las co-morbilidades no fueron diferentes en este grupo respecto a los pacientes sin prótesis. Salvo la menor frecuencia de fiebre ya comentada para estos pacientes, no se encontraron diferencias en la presentación clínica. Asimismo no hubo una asociación específica con alguna especie bacteriana. Tres de estos pacientes presentaron fístula o infección de herida operatoria y sólo cuatro se presentaron como IAAS.

\section{Manejo y evolución}

Los eventos fueron manejados en sala general (n: 15; $60 \%$ ), Unidad Intermedia (n: 8; 32\%) o Unidad Intensiva (n: $2 ; 8 \%$ ), con diferentes antimicrobianos y usando diferentes modalidades de aseo articular. El aseo fue efectuado en forma predominante por vía artroscópica (n: $11 ; 44 \%$ ) o por artrotomía (n: $9 ; 36 \%$ ) y en un solo caso por artrocentesis (4\%). En un caso adicional se retiró la prótesis involucrada (4\%) y en tres casos no se efectuó intervención articular alguna (12\%) debido a un cuadro de endocarditis infecciosa con evolución fulminante, un caso de infección asociada a prótesis de cadera sin remoción de ésta y un cuadro con limitaciones al esfuerzo terapéutico por leucemia de base. Se observó una preferencia por el tipo de abordaje quirúrgico aunque sin significación estadística. Así, 8 de las 11 intervenciones con artroscopia se efectuaron en rodilla y 6 de las 9 artrotomías en cadera. El número de aseos varió entre una y cuatro intervenciones, aunque la mayor parte fue sometido a un aseo ( 14 de 21 eventos con aseo; 66,7\%) o dos ( 5 de 21 eventos con aseo; $23,8 \%$ ). 
Todos los eventos, con excepción de un caso (4\%), recibieron tratamiento antimicrobiano. En 80\% (n: 20) tuvo un espectro adecuado y oportuno desde el comienzo (Tabla 7). En dos casos, fue inapropiado debido a la presencia de microorganismos resistentes, espectro inadecuado (bacilo gramnegativo sin cobertura inicial) en uno, o inicio tardío del tratamiento en pacientes con infección de prótesis de rodilla, en dos. La mayor parte de los pacientes recibió una terapia antimicrobiana secuencial parenteral-oral (n: $17 ; 6 \%$ ) y los restantes terapia parenteral (n: $6 ; 24 \%$ ) u oral (n: $1 ; 4 \%)$. Excluyendo los dos pacientes en terapia de supresión, la terapia parenteral tuvo una duración promedio de 19,3 días (rango 3-41), la terapia oral 37,4 días (rango 6-205) y la terapia secuencial parenteral-oral un promedio de 54,8 días (14-231). La duración del tratamiento parenteral (25,4 vs 15,4 días), oral (170 vs 18,9 días) o del tratamiento secuencial parenteral-oral (131,8 vs 32,6 días), fue significativamente más prolongada en pacientes con infección asociada a prótesis $(\mathrm{p}<0,05)$ que en aquellos pacientes sin prótesis. Trece de los 24 eventos que recibieron terapia antimicrobiana $(54,2 \%)$, fueron tratados con una combinación de antimicrobianos en algún momento.

\section{Desenlace}

El 32\% de los pacientes tuvo una respuesta clínica con recuperación completa (Tabla 8). Un 28\% (n: 7) adicional, tuvo un curso favorable determinado por la mejoría clínica pero con secuelas importantes (n: 3) (ver más adelante el detalle de todos los pacientes con secuelas), requerimiento de terapia de supresión por infección asociada a prótesis (n: 2), recaída del cuadro (n: 1) o tiempo de observación aún insuficiente para asegurar curación en una infección asociada a prótesis articular (n: 1). En cinco casos (20\%) el tratamiento fracasó, en dos casos por persistencia de los síntomas y en los otros tres por necesidad de remover la prótesis afectada. Finalmente, cuatro pacientes (16,7\%) fallecieron, representando $16 \%$ de los eventos (Tabla 8). Los decesos fueron explicados por progresión de una artritis de rodilla, por un cuadro de endocarditis infecciosa por $S$. aureus con foco articular asociado, por muerte en pabellón al retirar la prótesis afectada y un deceso por causas no relacionadas a la infección articular. La estadía hospitalaria promedio fue de 29,2 días (rango de 5-108 días). En esta serie no se encontraron factores asociados a un desenlace fatal o al desenlace compuesto muerte-ingreso a UCI.

Seis casos (24\%) presentaron secuelas. De ellos, tres casos evolucionaron hacia la artrosis de la articulación comprometida, en dos de ellos se debió instalar una prótesis y en el tercero efectuar una artrodesis. Otro caso evolucionó con luxación permanente de cadera, otro con dolor crónico y finalmente uno tuvo impotencia funcional permanente. El único factor asociado a la presencia de se-
Tabla 7. Características del tratamiento antimicrobiano en 24 pacientes con artritis séptica, Hospital Militar de Santiago, 2003-2013

\begin{tabular}{lrr|} 
Parámetro & $\mathbf{n}$ & $\%$ \\
Tratamiento & & \\
$\quad$ Reciben antimicrobianos & 23 & 96,0 \\
Espectro & & \\
$\quad$ Adecuado & 20 & 80,0 \\
$\quad$ Inadecuado & 4 & 20,0 \\
Vía administración & & \\
$\quad$ Parenteral, luego oral & 17 & 68,0 \\
$\quad$ Parenteral & 6 & 24,0 \\
Oral & 1 & 4,0 \\
\hline
\end{tabular}

Tabla 8. Evolución en 25 eventos de artritis séptica. Hospital Militar de Santiago, 2003-2013

\begin{tabular}{|lcc|} 
Evolución & $\mathbf{n}$ & $\%$ \\
Curación & 8 & 32,0 \\
Respuesta favorable & 7 & 28,0 \\
$\quad$ Secuelas* & 3 & \\
Terapia de supresión necesaria & 3 & \\
$\quad$ Recaída & 1 & \\
Fracaso & 5 & 20,0 \\
$\quad$ Persistencia de síntomas & 2 & \\
Remoción de la prótesis articular & 3 & \\
No evaluable por traslado & 1 & 4,0 \\
Fallecidos & 4 & 16,0 \\
Total & 25 & 100,0 \\
\hline *otros 3 casos en otros grupos. & & \\
\hline
\end{tabular}

cuelas fue una infección por BGNNF, en tres de seis casos con secuelas ( $p<0,05$ por prueba bilateral de Fisher).

\section{Discusión}

A pesar del número relativamente bajo de eventos identificados en 11 años de registro, esta serie contribuye al conocimiento de los cuadros de artritis séptica en Chile por la ausencia de series de casos publicadas previamente.

Los cuadros de artritis séptica emergen en pacientes adultos con condiciones que predisponen a desarrollar esta enfermedad, sistémicas o locales, siendo infrecuente su aparición en pacientes sin estos factores. Las condiciones locales que favorecen la artritis séptica quedaron representadas por la presencia de prótesis articulares en cadera o rodilla o procedimientos invasores articulares previos. Diferentes factores sistémicos participaron en esta serie, tales como diabetes mellitus, cáncer, diálisis, 
AR, daño hepático crónico y alcoholismo. Las condiciones locales o sistémicas permiten la proliferación de los microorganismos una vez que han llegado a la articulación comprometida, ya sea por vía hematógena -la más frecuente-, por inoculación o por contigüidad, estando los tres mecanismos presentes en nuestra serie. El perfil de estas condiciones en nuestro trabajo es concordante con lo descrito en la literatura médica ${ }^{6-9}$.

Una fracción relevante de esta serie aparece como IAAS, ya fuese como infecciones del sitio quirúrgico luego de la instalación de una prótesis articular o post artroscopia de rodilla. A pesar de que estas complicaciones no llegan a $1-2 \%$ del total, los centros que efectúan tales procedimientos en gran volumen, observan este tipo de complicaciones $^{10,11}$. Sin aumentar la proporción de casos complicados, la expansión de diferentes procedimientos diagnósticos o terapéuticos aumenta el número total de $\operatorname{casos}^{12}$. Factores propios del paciente como la existencia de AR, la presencia de una fractura alrededor de la rodilla o una infección precedente, aumentan el riesgo de infección en pacientes con prótesis ${ }^{13}$. En nuestro casos, no se dispuso de información sobre el número de prótesis articulares de cadera o rodilla instaladas o de artroscopias de rodilla efectuadas antes del año 2010. Sin embargo, de los casos observados desde el 2010 en adelante, sólo dos eventos corresponden a infecciones del sitio quirúrgico, ambos en prótesis de cadera registrados el año 2012 y con una tasa para ese año de $2,3 \%$, cifra inferior al percentil 75 de referencia nacional en Chile (3,3\%). Estos datos corroboran el bajo riesgo de complicaciones infecciosas relacionadas a la atención de salud para el gran volumen de pacientes que reciben una prótesis cada año y al mismo tiempo, resaltan el hecho de que para la mayor parte de los casos, representan un riesgo independiente y alejado del acto quirúrgico.

El dolor local y la impotencia funcional representaron las manifestaciones clínicas más relevantes (sobre el 90\%), no siendo la fiebre un signo universal. Este perfil es similar a lo señalado en revisiones sistemáticas ${ }^{1,8}$. Los cuadros de dolor articular tienen un amplio diagnóstico diferencial en adultos que incluyen no sólo artritis infecciosa, sino que también gota, pseudogota, AR, artritis reactiva, lupus eritematoso sistémico, enfermedad de Lyme, hemartrosis, artrosis, artropatía neuropática y otras condiciones. La probabilidad de una etiología infecciosa en un paciente con síntomas de artritis, aumenta en el caso de edad mayor de 80 años (likelihood ratio LR 3,5), diabetes mellitus (LR 2,7), AR (LR 2,5), cirugía articular reciente (LR 6,9), prótesis articular de cadera o rodilla (LR 3,1), infección cutánea (LR 2,8) e infección cutánea asociada a prótesis articular (LR 15) ${ }^{8}$. A pesar de que estas condiciones están reflejadas en esta serie, la de mayor valor diagnóstico (infección cutánea contigua) no fue prevalente y el resto tiene valores de LR que no son muy elevados. De esta manera, el diagnóstico definitivo requiere de una artrocentesis con estudio citoquímico y microbiológico con tinción de Gram y cultivo. No obstante, en un bajo porcentaje de los pacientes contamos con estudio del líquido articular en nuestro trabajo; en algunos pacientes se procedió directamente a aseo articular obviando esta práctica. Los hallazgos más relevantes y comunes fueron un porcentaje elevado de neutrófilos y concentraciones bajas de glucosa articular. Tanto un alto porcentajes de neutrófilos $(\geq 90 \%)$ como una concentración de glucosa articular $<27 \mathrm{mg} /$ $\mathrm{dL}$, han sido asociados a una mayor probabilidad de artritis séptica en revisiones sistemáticas y ambos rasgos fueron identificados en nuestros pacientes ${ }^{8}$. El recuento de leucocitos tuvo un menor rendimiento diagnóstico ya que no se detectaron cifras elevadas más categóricas de artritis séptica. La probabilidad aumenta progresivamente con recuentos $>25.000 / \mathrm{mm}^{3}(\mathrm{LR} 2,9),>50.000 / \mathrm{mm}^{3}(\mathrm{LR}$ $7,7) \mathrm{y}>100.000 / \mathrm{mm}^{3}$ (LR 28). ${ }^{8}$ Las pruebas de laboratorio general como leucocitosis $\left(>10.000 / \mathrm{mm}^{3}\right)$, elevación de la eritrosedimentación $(>30 \mathrm{~mm} / \mathrm{h})$ o aumento de la PCR ( $>100 \mathrm{mg} / \mathrm{L}$ ) no permiten acercarse al diagnóstico por su sensibilidad subóptima y especificidad limitada ${ }^{1,8,14}$. El diagnóstico oportuno de la artritis séptica es de suma importancia por las consecuencias devastadoras sobre la articulación y por la letalidad que ocasionalmente generan.

La mayor parte de las infecciones se asoció a cocáceas grampositivas y preferentemente a $S$. aureus, especie que ocupó la mitad de la serie. Otras cocáceas grampositivas correspondieron a otras especies del género Staphylococcus, algunas especies de Streptococcus y Enterococcus faecalis. La alta prevalencia de $S$. aureus es un hecho común en todas las series descritas, al igual que las infecciones por estreptococos $\beta$-hemolíticos ${ }^{8,15}$. Algunos casos de artritis por $S$. agalactiae han sido descritas previamente en Chile ${ }^{4}$. Los bacilos gramnegativos fueron infrecuentes e incluyeron también BGNNF. Tanto, los aislados del género Staphylococcus resistentes a cloxacilina como los BGNNF, tuvieron una tendencia a asociarse con cirugía o procedimientos articulares previos, lo que puede orientar al uso de esquemas de mayor espectro en estas condiciones. No se encontraron en esta serie, aislados de Neisseria gonorrhoeae, probablemente por el mayor promedio de edad del grupo analizado, ni tampoco casos asociados a Brucella spp., Salmonella spp. o Streptococcus pneumoniae $^{9,16,17}$. Las infecciones articulares por $S$. pneumoniae se asocian en una fracción de los casos a compromiso poliarticular, neumonía y/o meningitis ${ }^{9,18}$. En Chile, este agente ha sido descrito en el contexto de casos con bacteriemia alcanzando a $10 \%$ en una serie de 40 pacientes $^{5}$. Por su parte, el compromiso articular en cuadros de brucelosis es de predominio poliarticular, con compromiso periférico y axial (sacroileítis-espondilodiscitis) y puede tener antecedentes de exposición a alimentos de riesgos o de tipo laboral ${ }^{16}$. La existencia de bacteriemia no es infrecuente 
en pacientes con artritis séptica y en los porcentajes registrados en este estudio ${ }^{19,20}$. Su presencia estuvo asociada al compromiso de conciencia y fue rara vez observada en pacientes con cirugía articular precedente.

Las imágenes aportan poco a la confirmación del diagnóstico debido a su baja especificidad, alteraciones tardías o interferencias por cuerpos extraños ${ }^{8,21,22}$. Por ejemplo, en la radiografía convencional el aumento de tejidos blandos, la erosión de la corteza y la presencia de osteopenia pueden verse en causas no infecciosas de artritis $^{22}$. De la misma manera, en estudios con RM se observa una tendencia a una mayor frecuencia de erosiones óseas asociado a edema de la médula ósea pero sin ser un rasgo significativo. La existencia de engrosamiento sinovial, con o sin refuerzo del medio paramagnético, fluido articular aumentado o heterogéneo o la erosión del cartílago, no son específicos y se observan con frecuencias similares en otras causas de artritis ${ }^{21}$. Las alteraciones ecográficas encontradas en este trabajo fueron frecuentes y sugerentes pero no han sido sometidas a un análisis sistemático para evaluar su rol ante otras causas de artritis. Es probable que al igual que lo comentado para la radiografía convencional y la RM, sean de valor limitado. Como se registró en este trabajo, la radiología convencional, la TAC y los estudios de medicina nuclear fueron de muy baja utilidad y no parecen obedecer a un algoritmo de estudio progresivo. De hecho, la solicitud de TAC y de estudios de medicina nuclear no parece ser especialmente útil en pacientes con prótesis o material de fijación o cirugía reciente y la radiografía convencional queda restringida al infrecuente hallazgo de radiolucidez en un paciente con prótesis. A pesar de las limitaciones para establecer el diagnóstico, estos exámenes son útiles para decidir un mejor abordaje quirúrgico o exploratorio.

Las articulaciones comprometidas en esta serie son concordantes a lo observado en otras, con predominio del compromiso de rodilla y cadera ${ }^{8,9}$. No se observaron casos de afección sacroilíaca o esternoclavicular, probablemente por la baja frecuencia reportada ${ }^{23,24}$.

El tratamiento está dirigido a controlar el proceso inflamatorio, erradicar el agente y prevenir la mortalidad y secuelas. Aún así, el pronóstico es adverso en pacientes mayores, en aquellos con AR, prótesis articular o con co-morbilidad importante. El tratamiento se debe iniciar inmediatamente después de completar la evaluación clínica y tomar los cultivos. La tinción de Gram y la presencia de factores de riesgo para agentes resistentes deben guiar la terapia antimicrobiana la que debe tener espectro adecuado sobre microorganismos grampositivos y gramnegativos. Como se observó, la presencia de $S$. aureus resistentes o de BGNNF parece depender de una exposición previa a la atención de salud, lo que permite orientar el tratamiento inicial. A diferencia de este trabajo, en algunas regiones los aislados de $S$. aureus resistentes a cloxacilina han sobrepasado a los aislados susceptibles en pacientes con artritis séptica lo que tiene grandes implicancias en la selección empírica inicial de antimicrobianos y su frecuencia por lo tanto debe ser monitorizada ${ }^{25}$. Las infecciones asociadas a $N$. gonorrhoeae se asocian a pacientes jóvenes sexualmente activos, lesiones cutáneas y poliartritis migratoria con tenosinovitis ${ }^{7}$. En estos casos es necesario incluir cefalosporinas de tercera generación por la resistencia a penicilinas y quinolonas.

En el tratamiento, la vía parenteral es recomendada en la fase inicial para asegurar mejores concentraciones tisulares, un efecto bactericida y un control rápido sobre el proceso inflamatorio. Teniendo el espectro adecuado, la experiencia publicada no favorece a determinado antimicrobiano, aunque cloxacilina respecto a ceftriaxona, se ha asociado a una mayor tasa de efectos adversos, probablemente por alergia o flebitis ${ }^{20}$. Permanecen en la nebulosa la duración de la fase parenteral y la duración total del tratamiento antimicrobiano debido a la falta de estudios randomizados. Por ejemplo, se recomienda un tratamiento de dos semanas por vía parenteral para infecciones estreptocóccicas, tres a cuatro semanas para las estafilocóccicas y bacilos gramnegativos y más de cuatro semanas en pacientes inmunosuprimidos o pacientes con articulaciones muy dañadas. Otros autores recomiendan dos semanas de terapia parenteral y dos semanas adicionales por vía oral ${ }^{19}$. En series recientes, la duración del tratamiento parenteral no parece influir en la tasa de recaída si se usa al menos por siete días con una fase adicional por vía oral. No se han podido registrar diferencias en el resultado al comparar tratamientos totales por dos semanas versus tratamientos más prolongados ${ }^{19}$. En grandes series que no han incluido pacientes con prótesis articular, los factores que participan en una recaída incluyen la inmunosupresión, infección por bacilos gramnegativos o la ausencia de algún procedimiento quirúrgico pero no la duración de la terapia antimicrobiana ${ }^{19}$. En concordancia con estos comentarios, observamos una fuerte preferencia por el uso de esquemas parenterales, una dispersión en la duración del tratamiento y esquemas más prolongados en casos de un cuerpo extraño presente.

$\mathrm{El}$ aseo articular es un aspecto esencial en el tratamiento, permitiendo mejorar la vascularización, descomprimir la articulación, remover microorganismos y también mediadores de la cascada inflamatoria. No hay evidencia, en ensayos randomizados o controlados, para preferir algún método de lavado articular sobre otro y las alternativas de acceso incluyen la artrocentesis, artroscopia o artrotomía ${ }^{26-28}$. La opción por alguna de éstas se basa en la preferencia y experiencia local, acceso al recurso, la articulación comprometida, presencia o ausencia de prótesis articular o material de fijación y gravedad del paciente. Así, en casos de infección asociada a una prótesis articular, se aplican de preferencia procedimientos 
quirúrgicos, al igual que sucede si hay compromiso de cadera o ante la presencia de pus muy viscosa. En algunas series, el drenaje artroscópico se ha asociado a una menor estadía hospitalaria, menor número de re-intervenciones o mayor recuperación funcional respecto a la artrotomía $y$, por su parte, la artrocentesis repetida se ha asociado a una menor necesidad de rehabilitación pero la experiencia reportada no está basada en estudios controlados prospectivos debido a la baja frecuencia de esta enfermedad y es probable que haya sesgos de selección de los $\operatorname{casos}^{6,27-30}$. Por otra parte, la visualización directa de la cavidad articular y la posibilidad de efectuar un aseo completo y desbridamiento de sinequias articulares sólo puede ser lograda en caso de aseo artroscópico o artrotomía pero no en una artrocentesis. Aún así, la artrocentesis podría ser una medida suficiente para el manejo de artritis séptica en pacientes seleccionados y articulaciones menores. En nuestra serie, las tres aproximaciones fueron utilizadas aunque predominó el abordaje artroscópico y se observó una preferencia por el tipo de abordaje según la articulación comprometida.

Las principales secuelas en los pacientes con artritis séptica corresponden a dolor debilitante, limitaciones del rango articular y artrosis. En nuestro trabajo, estas secuelas estuvieron presentes, en un alto porcentaje y asociadas significativamente a infecciones por BGNNF.

Además de los diferentes procedimientos invasores o quirúrgicos que sufren estos pacientes, incluyendo aseos articulares o remoción de prótesis previamente instalada, en nuestra experiencia también se pudo observar que los pacientes con artritis séptica presentan una morbilidad y hospitalización prolongada, que requieren atención en unidades críticas o semicríticas, que existe fracaso del tratamiento médico-quirúrgico, con recaídas, secuelas y que hay una letalidad asociada a estos cuadros, tal como ha sido descrito previamente ${ }^{4,9}$.

La naturaleza retrospectiva de este trabajo impidió contar con información clínica para efectuar mayores análisis de asociación de ciertos factores con resultados terapéuticos o la justificación de ciertas modalidades de terapia. El seguimiento post egreso no fue uniforme en estos pacientes y aspectos tales como el dolor o el grado de limitación funcional no aparecen claramente establecidos en los registros médicos en todos los pacientes como para asegurar el porcentaje de secuelas observado. Asimismo, el bajo número de casos encontrados impide explorar con mayor precisión ciertas asociaciones estadísticas o tendencias. En once años de análisis, los equipos tratantes necesariamente cambiaron y con ello las preferencias terapéuticas, incluyendo las intervenciones quirúrgicas, lo que pudo haber afectado los resultados clínicos. Las terapias antimicrobianas aplicadas quedaron a criterio del médico tratante y no obedecen a guías específicas de tratamiento. No obstante estas limitaciones, este estudio da cuenta por primera vez de una serie de pacientes adultos afectados con artritis séptica y permite profundizar en el conocimiento de esta patología.

Agradecimientos. Los autores desean agradecer a Mario Orrego del Departamento de Traumatología del Hospital Militar de Santiago por sus valiosos comentarios y revisión crítica del manuscrito.

\section{Resumen}

Antecedentes: Los cuadros de artritis séptica son esporádicos pero de elevada morbilidad y no hay publicaciones en Chile que permitan orientar el tratamiento de ellos. Objetivos: Caracterizar un grupo de pacientes con cuadros de artritis séptica confirmados microbiológicamente. Pacientes y Métodos: Serie de casos. Resultados: Un total de 24 pacientes con 25 eventos de artritis séptica fue identificado entre el 2003 y agosto de 2013. La edad promedio fue de 68,3 años (24-94) y 91,7\% tuvo condiciones que predisponen. Las manifestaciones clínicas dominantes fueron dolor ( $92 \%$ ) e impotencia funcional (95,7\%), 64\% presentó fiebre y $28 \%$ tuvo hipotensión arterial. Un 90,6\% tuvo PCR > 100 mg/L. Las cocáceas grampositivas fueron los microorganismos más frecuentes $(81,5 \%)$, predominando Staphylococcus aureus $(48,1 \%)$ y cuatro cepas estafilocóccicas presentaron resistencia a cloxacilina $(26,7 \%)$. Las cepas resistentes tendieron a estar asociadas a pacientes con cirugía articular previa (p: $0,055)$ y todos los casos asociados a bacilos gramnegativos no fermentadores tenían antecedentes de hospitalización reciente o cirugía articular previa. Nueve eventos (36\%) se asociaron a bacteriemia. Un 32\% de los pacientes tuvo curación, $28 \%$ un curso favorable, $20 \%$ fracaso y $16,7 \%$ falleció. Un 24\% quedó con secuelas. Conclusiones: Los cuadros de artritis séptica son infrecuentes, afectan en su mayor parte a pacientes con factores que predisponen, se presentan con dolor e impotencia funcional, a veces fiebre, hipotensión arterial o bacteriemia y generalmente con PCR $>100 \mathrm{mg} / \mathrm{L}$. Se asocian a cocáceas grampositivas, especialmente $S$. aureus, incluyendo aislados resistentes a cloxacilina. La letalidad, fracaso del tratamiento y secuelas no son despreciables. 


\section{Referencias bibliográficas}

1.- Carpenter C R, Schuur J D, Everett W W, Pines J M. Evidence-based diagnostics: adult septic arthritis. Acad Emerg Med 2011; 18: 781-96.

2.- Gil G, Foster C, Neira O, Palma S, Basualdo J, Heredia C, et al. Artritis por Cryptococcus neoformans en un adulto mayor: Presentación de un caso y revisión. Rev Chilena Infectol 2006; 23: 330-5.

3.- Mardones R, Rojas C, Carmona M. Artritis séptica de la sínfisis del pubis. Rev Med Chile 2007; 135: 1040-3.

4.- Mendoza L, Letelier C, Pérez C, Bambs C, García P. Infecciones invasoras causadas por Streptococcus $\beta$ hemolítico grupo G. Rev Chilena Infectol 1999; 16: 27-32.

5.- Noriega L M, González P, Canals C, Michaud P. Streptococcus pneumoniae septicemia. Analysis of 40 cases. Rev Med Chile 1994; 122: 1385-92.

6.- Erskine P, Hinzpeter J, Gross K, Catalán J. Artritis séptica: ventajas del drenaje artroscópico. Rev Hosp Clin Univ Chile 1999; 10: $5-10$

7.- García De La Torre I, Nava Zavala A. Gonococcal and nongonococcal arthritis. Rheum Dis Clin North Am 2009; 35: 63-73.

8.- Margaretten ME, Kohlwes J, Moore D, Bent S. Does this adult patient have septic arthritis? JAMA 2007; 297: 1478-88.

9.- Ross J J, Saltzman C L, Carling P, Shapiro D S. Pneumococcal septic arthritis: review of 190 cases. Clin Infect Dis 2003; 36: 319-27.

10.- Erskine P, Gross K, Galanti A, Infante C, Orizola A, Catalán J. Cirugía artroscópica de rodilla. Rev Hosp Clin Univ Chile 2000; 11: 137-42.

11.- Paulós J, Wagner E, Lisoni A. Artroplastía total de rodilla con prótesis de estabilización posterior: 10 años de experiencia. Rev Chil
Ortop Traumatol 2001; 42: 29-36.

12.- Geirsson Á J, Statkevicius S, Víkingsson A. Septic arthritis in Iceland 1990-2002: increasing incidence due to iatrogenic infections. Ann Rheum Dis 2008; 67: 638-43.

13.- Jämsen E, Huhtala H, Puolakka T, Moilanen T. Risk factors for infection after knee arthroplasty. A register-based analysis of 43,149 cases. J Bone Joint Surg Am 2009; 91: 38-47.

14.- Li S F, Henderson J, Dickman E, Darzynkiewicz R. Laboratory tests in adults with monoarticular arthritis: Can they rule out a septic joint? Acad Emerg Med 2004; 11 : 276-80.

15.- Vispo Seara J L, Barthel T, Schmitz H, Eulert J. Arthroscopic treatment of septic joints: prognostic factors. Arch Orthop Trauma Surg 2002; 122: 204-11.

16.- Buzgan $\mathrm{T}$, Karahocagil M K, Irmak $\mathrm{H}$, Baran A I, Karsen H, Evirgen O, et al. Clinical manifestations and complications in 1028 cases of brucellosis: a retrospective evaluation and review of the literature. Int J Infect Dis 2010; 14: e469-78.

17.- Katsoulis E, Pallett A, Bowyer G W. Septic arthritis of the knee by Salmonella Montevideo. Ann R Coll Surg Engl 2004; 86: 272-4.

18.- Raad J, Peacock J E Jr. Septic arthritis in the adult caused by Streptococcus pneumoniae: A report of 4 cases and review of the literature. Semin Arthritis Rheum 2004; 34: 559-69.

19.- Uçkay I, Tovmirzaeva L, Garbino J, Rohner P, Tahintzi $\mathrm{P}$, Suvà $\mathrm{D}$, et al. Short parenteral antibiotic treatment for adult septic arthritis after successful drainage. Int J Infect Dis 2013; 17: e199-e205.

20.- Wieland B W, Marcantoni J R, Bommarito K M, Warren D K, Marschall J. A retrospective comparison of ceftriaxone versus oxacillin for osteoarticular infections due to methicillinsusceptible Staphylococcus aureus. Clin Infect Dis 2012; 54: 585-90.
21.- Graif M, Schweitzer M E, Deely D, Matteucci T. The septic versus nonseptic inflamed joint: MRI characteristics. Skeletal Radiol 1999; 28: 616-20.

22.- Rousseau I, Cardinal E, Raymond-Tremblay D, Beauregard C G, Braunstein E M, Saint-Pierre A. Gout: radiographic findings mimicking infection. Skeletal Radiol 2001; 30: 565-9.

23.- Hermet M, Minichiello E, Flipo R M, Dubost J J, Allanore Y, Ziza J M, et al. Infectious sacroiliitis: a retrospective, multicentre study of 39 adults. BMC Infect Dis 2012; 12: 305.

24.- Womack J. Septic arthritis of the sternoclavicular joint. J Am Board Fam Med 2012; 25: 908-12.

25.- Frazee B W, Fee C, Lambert L. How common is MRSA in adult septic arthritis? Ann Emerg Med 2009; 54: 695-700.

26.- Broy S B, Schmid F R. A comparison of medical drainage (needle aspiration) and surgical drainage (arthrotomy or arthroscopy) in the initial treatment of infected joints. Clin Rheum Dis 1986; 12: 501-22.

27.- Manadan A M, Block J A. Daily needle aspiration versus surgical lavage for the treatment of bacterial septic arthritis in adults. Am J Ther 2004; 11: 412-5.

28.- Ravindran V, Logan I, Bourke B E. Medical vs surgical treatment for the native joint in septic arthritis: a 6-year, single UK academic centre experience. Rheumatology 2009; 48: 1320-2.

29.- Sammer D M, Shin A Y. Comparison of arthroscopic and open treatment of septic arthritis of the wrist. J Bone Joint Surg Am 2009; 91: 1387-93.

30.- Wirtz D C, Marth M, Miltner O, Schneider U, Zilkens K W. Septic arthritis of the knee in adults: treatment by arthroscopy or arthrotomy. Int Orthop 2001; 25: 239-41. 